\title{
THE MEDICAL ASPECT OF HEMATURIA.'
}

\author{
BY EDWIN C. WARNER, M.D., M.R.C.P.
}

Hematuria is not a diagnosis it is a symptom, and so we must treat it as such and try and find the cause. It may first be seen as a medical condition although the case may later have to be sent to a surgeon for special examinations or for operation, and so it is necessary to mention certain surgical conditions giving rise to it.

Hæmaturia must be distinguished from the rarer condition hæmoglobinuria. In this latter free hæmoglobin occurs in the urine, being excreted as such by the kidneys, that is, no red cells occur in the urine. Hence the urine tends to be clear. Hæmaturia signifies that red cells are present. It may be that most of the red cells have liberated their hæmoglobin, but a sufficient number always remain to distinguish the condition. Urine is not an isotonic solution, it is rarely neutral in reaction, and in addition some urines are particularly powerful in containing hæmolysing agents. In hæmaturia the urine is more opalescent due to the suspension of red cells present. Blood in the urine is also recognized by the guaiacum or benzidine tests. These tests are much more delicate when ozonic alcohol is used rather than ozonic ether, as the latter only forms a layer on the surface of the urine and greatly decreases the delicacy of the reaction. One fallacy of this reaction, sometimes forgotten, is that iodide in any form will give the same colour reaction.

The source of bleeding in the urinary tract may be urethral, vesical, or renal. It is most important to determine first from which of these three sources the blood originates. The differences may be summarized briefly:-

\begin{tabular}{|c|c|c|c|}
\hline $\begin{array}{l}\text { Colour of blood ... } \\
\text { Mixture with urine }\end{array}$ & $\begin{array}{l}\text { Urethral } \\
\text { Bright red ... } \\
\text { Appears first, }\end{array}$ & $\begin{array}{l}\text { Vesical } \\
\text { Often not quite bright red } \\
\text { Some mixture with urine, }\end{array}$ & $\begin{array}{l}\text { Renal } \\
\text { Often "smoky" } \\
\text { Intimately mixed with urine }\end{array}$ \\
\hline Clots & $\begin{array}{l}\text { rare } \\
\text { Rare }\end{array}$ & $\begin{array}{l}\text { but most blood appears last } \\
\text { Sometimes large clots }\end{array}$ & $\begin{array}{l}\text { Sometimes } \\
\text { clots" }\end{array}$ \\
\hline Occurrence & Intermittent & $\begin{array}{l}\text { May be more or less con- } \\
\text { tinuous }\end{array}$ & Continuous for a few days \\
\hline $\begin{array}{l}\text { Pain or tenderness } \\
\text { Microscopically ... }\end{array}$ & $\begin{array}{c}\text { In urethra } \ldots \\
\ldots\end{array}$ & $\begin{array}{l}\text { In hypogastrium } \ldots \\
\text { Excess of bladder squames }\end{array}$ & $\begin{array}{l}\text { In loins } \\
\text { Excess of renal epithe } \\
\text { or casts }\end{array}$ \\
\hline
\end{tabular}

Happily very few causes of hæmaturia give rise to bleeding from more than one of these levels at a time, but in a difficult case cystoscopy may be necessary to determine the site of hæmorrhage.

Urethral and vesical bleeding are the least common from a medical standpoint and so will be briefly discussed first.

Urethral bleeding usually occurs due to a foreign body or stone in the urethra, to acute urethritis, to a gonococcal abscess bursting into the urethra, or not uncommonly from a caruncle, or in boys from the external urinary meatus. In this last, as a result of trauma and uncleanliness infection of the meatus not uncommonly occurs and the lips of the meatus may become sealed. At the commencement of subsequent micturition this is broken open and streaks of blood appear. A local ointment and an antiseptic dressing soon effect a cure.

1 Synopsis of lecture delivered at the Medical Society of London, being the first of a series of lectures on "Renal Disease," given for the Fellowship of Medicine. 
Vesical bleeding may be profuse or slight (even microscopic). It arises in acute cystitis, and the hæmorrhage may be made much worse, with a corresponding increase in frequency and even strangury when hexamine is given. Hexamine liberates formalin in the bladder with an acid urine, and when large doses are given as in the treatment of cholecystitis, hæmorrhage may even occur from the wall of a normal bladder. Still more so is this true with an inflamed bladder, and hexamine should never be given at this stage. If dysuria and hæmorrhage are present due to hexamine, these can be readily controlled as soon as the urine is made alkaline.

An enlarged prostate may cause hæmaturia due to congestion of the base of the bladder, or even rupture of varicose veins in this situation. Then, again, copious hæmorrhage may occur from a papilloma or a carcinoma of the bladder, and in infection with bilharzia hæmatobia we have a tropical cause to mention.

The ureter may be the primary source of hæmorrhage as in a recent case seen with $\mathrm{Mr}$. Ogier-Ward where a large calcifying tuberculous gland was found ulcerating into the ureter-usually only on the right side-and causing attacks of painless hæmaturia.

Most cases of purely medical interest are due to renal hæmorrhage. This group is so large that it is convenient to consider it under the headings of $(a)$ causes arising outside the kidney; $(b)$ causes arising in the kidney substance; and $(c)$ causes arising in the pelvis of the kidney.

(a) Causes arising outside the kidney give rise to unilateral bleeding. First trauma must be mentioned. Hamophilia has been mentioned as a cause of inexplicable bleeding, but it is very doubtful if hæmophilia ever gives rise to renal hæmorrhage apart from trauma. Aberrant renal vessels, and nephroptosis may occasionally cause a little hæmorrhage probably as a secondary result to the hydronephrosis they cause, and the subsequent congestion of the renal pelvis. The above causes have been briefly discussed as they are essentially surgical.

(b) Causes arising in the kidney substance. First and foremost is acute inflammation, or acute nephritis. A distinguishing feature here is the presence of casts and of excessive numbers of renal epithelial cells. An occasional hyaline cast is present in normal urine as an expression of the normal wear and tear of the kidneys, but an excessive number of hyaline casts, or epithelial, blood, or granular casts indicate acute nephritis. Fatty casts always indicate chronic nephritis as they take many months to form, even when the case appears otherwise to be one of acute nephritis. Acute nephritis exists in two main groups : (I) acute focal glomerulo-tubular nephritis, and (2) acute general glomerulo-tubular nephritis.

Acute focal nephritis is more common in children and young adults, and usually arises due to a mild streptococcal septicæmia perhaps originating from a hæmolytic streptococcal tonsillitis. The organisms can be isolated from the urine, and the nephritis occurs during the tonsillitis. The kidneys are swollen, perhaps giving a dull ache in the loins, but there are no signs of renal failure-no oliguria, no odema, no rise of bloodpressure or rise in blood urea. There are always sufficient normally functioning glomerulo-tubular systems to prevent renal failure in any of its forms. In these cases the amount of blood is often large, and the amount of albumin is only in proportion to the amount of blood present. The prognosis is usually very good, largely because no extra strain is thrown on the inflamed glomeruli and tubules. Within a week or so the hæmorrhage has largely ceased, and the remaining trace of albumin goes soon 
afterwards. It is this group that has given rise to the old observation, that the more sudden and profuse the initial hæmorrhage in acute nephritis, the better the ultimate prognosis.

Acute diffuse glomerulo-tubular nephritis is typified by scarlatinal nephritis which makes its appearance usually in the third week after the initial sore throat. Osman has shown that when this type occurs after non-scarlatinal tonsillitis, it is usually again in the second and third weeks. The damage is done here by the streptococcal toxins, not by the bacteria themselves, which accounts for there being no streptococci in the urine and for the more diffuse nature of the lesion. Hence this type gives signs of renal failureœdema, an initial raised blood-pressure, urea and chloride retention, and a diminished volume of urine until the "critical diuresis" occurs. In these cases also the amount of albumin is definitely in excess of that due to the blood present, and the hæmorrhage is less free. In correspondence with all these points the ultimate prognosis is less good, and a greater number of cases develop into chronic nephritis.

Under this same heading of acute diffuse nephritis can be mentioned the cases occurring as a result of drugs-cantharides, turpentine, phenol and its derivatives, mercury salts, and salicylates. Perhaps one of the commonest is sodium salicylate, and in view of Osman's work it is of interest to note that sodium salicylate develops an acidosis and symptoms of salicylism which are both prevented if an equal dose of sodium bicarbonate is given simultaneously.

Hæmaturia in chronic nephritis, if continuing week after week, even only in the form of red cells, means progressive damage to the kidneys, and has a grave significance. But sometimes in a case of chronic nephritis there is a sudden burst of blood. This may mean one of two things : either an acute or a subacute relapse of the nephritis, which manifests itself also by more œdema and more albuminuria ; or else that a hæmorrhage has occurred as a result of a raised blood-pressure, which is of the same significance as a cerebral hæmorrhage in these cases. In this latter instance the odema is not increased, the albumin is only slightly raised, and the blood-pressure may even be slightly lowered. Such may occur in the high blood-pressures associated with arteriosclerosis, polycystic disease of the kidneys or in polycythæmia.

Tuberculosis of the kidney produces hæmaturia in 75 per cent. of cases (Fullerton). The bleeding may be macroscopic or microscopic, and may be the first sign. Just as a frank hæmoptysis may be the first evidence of pulmonary tuberculosis, hæmaturia may be the first sign of renal tuberculosis, but on the whole this is rare. In a suspected case, symptoms of frequency and pain, associated with pus and albumin, yet on culture the urine is sterile, should always raise the suspicion of tuberculosis. A sterile pyuria is often tuberculous. There may be other leading signs such as an enlarged kidney, or signs in the genital tract to help towards the diagnosis. The caseous focus in the kidney may discharge tuberculous material intermittently or constantly into the urine in cases of "closed" and "open" tuberculosis, and so it may be necessary to examine the deposit in several twenty-four-hour specimens of urine before the organism is isolated. Guineapig inoculation and instrumental examinations may both be necessary in confirmation of a difficult case.

Bilharzia hæmatobia only produces involvement of the kidney when the bladder is already extensively invaded.

Infarction of the kidney may be an early or a late sign of infective endocar ditis. 
In any case, it is a valuable confirmatory sign, showing itself sometimes with pain or more commonly with albumin and blood in the urine, occurring in periodic attacks.

Congestion of the kidney occurs in a number of different conditions. The commonest group is associated with advanced right-sided heart failure. Here the decreased volume of the urine, the amount of albumin and the amount of blood vary directly with increase or decrease of the congestion of the kidney, and are of help in indicating increase or decrease in the heart failure.

Sudden congestion of the kidneys and hæmaturia sometimes occurs after rapid catheterization of a distended bladder, probably as a result of sudden relief of a bilateral hydronephrosis. It can be avoided by more gradual emptying of the bladder, and if hæmaturia and often suppression and uræmia do occur, it may be necessary to relieve the tension in the kidneys by decapsulation.

Yet another cause is thrombosis of the renal vein. This most commonly occurs in septicæmic conditions, particularly streptococcal, and the sudden hæmaturia with a sudden tender enlarged kidney is always suggestive of this condition.

Congestion causing hæmaturia may also occur when a person who has been long recumbent suddenly gets on to his feet. A series of these cases was recently described by H. E. Wiison : in 150 cases of fractured femur, 23 showed renal colic and hæmaturia ; in 16 cases the hæmaturia was visible and in 7 was microscopical. The bleeding particularly occurred on the second day, and was much less on the third and fourth days. It was not due to calculi, and appeared to relate to the sudden congestion after months in a recumbent position.

Orthostatic and kyphotic albuminuria are sometimes associated with a few red cells in the urine, but never with macroscopic blood. These are believed to be due to passive congestion, perhaps in the kyphotic type, accentuated by the abnormal positions of organs causing the left renal vein to be pressed upon by the descending aorta.

Purpura often causes hæmaturia, and here apart from visible purpura elsewhere, this condition is suggested when the amount of albumin present is only such as is due to the hæmorrhage. The amount of bleeding may be small or large, and sometimes in thrombocytopenic purpura the amount of blood-loss may be such as to cause alarm. Such cases can be distinguished by the prolonged bleeding time and the low blood-platelet count.

Scurvy may cause hæmaturia, and in a suspicious case the gums and bones must be examined. If the hæmorrhage has not ceased within three days of intensive treatment with fruit juice, the diagnosis must be revised.

New growths in the kidney are usually hypernephromata or adenocarcinomata. At a late stage when the diagnosis is obvious, operation is too late to effect a cure, and we must not wait till an obvious lump appears. A hypernephroma is one of the commonest causes of painless hæmaturia, and if a patient shows two attacks of unilateral unexplained painless hæmaturia he should be explored to exclude this condition.

Essential hæmaturia is a name given to a group of cases with unilateral hæmaturia which may be slight or severe, and which is usually accompanied by paroxysmal or continuous renal pain. These cases were thought to be due to unilateral nephritis, but this condition does not occur (Kummel), and the kidneys which have been removed for essential hæmaturia show no macroscopic or microscopic evidence of nephritis. It must be admitted that the cause is unknown, but a striking cessation of the hæmorrhage 
follows shortly after nephrotomy-even when the hæmorrhage has persisted for months previously.

Conditions within the kidney causing hæmaturia include calculi. A large branched calculus-the "large silent stone"-rarely produces hæmorrhage. It is the small, more freely mobile stone that does so. The bleeding usually occurs in the next specimen passed after the colic, and the urine contains epithelial cells and sometimes crystals which signify the condition. Occasionally painless hæmaturia is caused by a calculus. Oxaluria may cause considerable hæmaturia. This may supervene after foods rich in oxalates-rhubarb, artichokes, tomatoes, strawberries-or after concentration of the urine by sweating. Associated with the oxaluria there is often scratching of the urethra on micturition, producing pain which is very suggestive. The oxalate crystals occur only in an alkaline urine, and the administration of sodium acid phosphate will lead to a rapid cessation of pain and of hæmorrhage. To prevent occurrence it is essential to drink copiously, and to avoid waters containing much calcium. Also excessive sugar ingestion is unwise, as this can form oxalic acid by bacterial fermentation in the intestines.

Acute pyelitis rarely causes much hæmaturia, but new growths of the pelvis of the kidney, such as papillomata or carcinomata, may do so. A nævoid condition of the apex of the pyramids can be the cause of unexplained hæmaturia, but this is rarely diagnosed apart from exploration.

To locate the cause of hæmaturia may be simple, or on the other hand may require the combined skill of the physician, the surgeon and the pathologist to elucidate a difficult case.

\section{A CASE OF SILICOSIS.}

By ERNEST FLETCHER, M.A., M.B., M.R.C.P.

Assistant Physician, Queen Mary's Hospital, Stratford; Medical Registrar, Royal Chest Hospital.

J. B., aged 48 , a fire-bricklayer.

Has had a cough, tightness in the chest, and increasing dyspnœea, for seven years. For the last two years has had occasional streaky hæmoptysis, with abundant foul sputum, and during the last month has had two very large hæmoptyses of a pint each. The weight is steady and the appetite good.

Past History.-No acute illness in the past except an attack of pleurisy one year ago.

Family History.-No history of pulmonary tuberculosis. Fellow-workers suffer from colds and coughs.

On examination, the patient was markedly cyanosed, fingers are clubbed, marked kyphosis.

Chest : "Pigeon-chested," with prominent sternum. Wide intercostal angle, with raising and eversion of lower costal margin.

Heart: A.C.D. goes halt an inch to the right of the sternum, third rib above, the apex beat is in the fifth space half an inch inside the nipple line. Sounds, forcible. Marked epigastric pulsation.

Lungs: Percussion note is resonant over the upper half of the chest, except at the right apex in front. Impaired note at both bases with fine crepitations, universal 